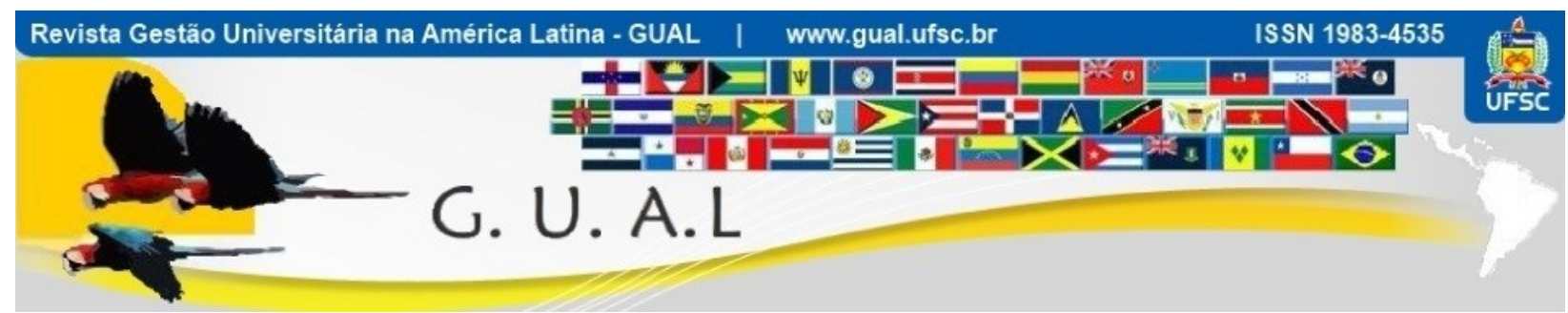

DOI: http://dx.doi.org/10.5007/1983-4535.2014v7n1p257

\title{
MUDANÇAS ESTRATÉGICAS EM UNIVERSIDADE COMUNITARIA: UM ESTUDO DESENVOLVIDO NO RIO GRANDE DO SUL
}

\section{STRATEGIC CHANGE IN COMMUNITY COLLEGE: A STUDY CONDUCTED IN RIO GRANDE DO SUL}

\author{
Andressa Hennig Silva, Doutoranda \\ Universidade Federal de Santa Maria - UFSM \\ andressahs@ibest.com.br \\ Carlos Eduardo Tavares, Mestre \\ Universidade de Cruz Alta - UNICRUZ \\ etavares@unicruz.edu.br \\ Gilnei Luiz de Moura, Doutor \\ Universidade Federal de Santa Maria - UFSM \\ mr.gmoura.ufsm@gmail.com \\ Marçal Silveira, Graduado \\ Universidade de Cruz Alta - UNICRUZ \\ marcal_silveira@hotmail.com
}

Recebido em 13/setembro/2013

Aprovado em 06/dezembro/2013

Sistema de Avaliação: Double Blind Review

Esta obra está sob uma Licença Creative Commons Atribuição-Uso. 


\title{
RESUMO
}

Influenciadas pelo ambiente competitivo contemporâneo, as universidades, especialmente as comunitárias e particulares, necessitam acelerar o processo de mudança. Nesse sentido, este trabalho tem como objetivo identificar as mudanças estratégicas ocorridas em uma universidade comunitária localizada no interior do Rio Grande do Sul, no período compreendido entre 2005 até 2011. Para tanto, foi realizado um estudo de caso. O levantamento dos dados ocorreu através de entrevistas semiestruturadas com gestores da instituição de ensino. A partir da analise e interpretação dos dados, foi verificado que houve, aproximadamente, seis mudanças estratégicas significativas no período estudado. As causas dessas mudanças se deram por diversos motivos, tais como, a necessidade de reorganizar a estrutura de gestão, redimensionamento da infraestrutura da instituição a realidade de mercado. Conclui-se que as mudanças ocorreram a partir da percepção dos gestores da época, a cerca da necessidade de modificar a postura da Universidade, ou seja, a necessidade de desenvolver uma nova mentalidade institucional, reorganizando e redirecionando suas estratégias. Observou-se também que a instituição necessitou reorganizar sua gestão, ampliando o processo de participação comunitária nas tomadas de decisões da organização, tendo em vista a característica institucional comunitária.

Palavras-Chave: Universidade. Estratégia. Mudança Estratégica.

\begin{abstract}
Influenced by contemporary competitive environment, the universities, especially the community and individuals, need to accelerate the process of change. In this sense, this work aims to identify strategic changes occurring in a community college located in the interior of Rio Grande do Sul, in the period 2005 to 2011. Therefore, we performed a case study. Data collection occurred through semi-structured interviews with managers of the educational institution. From the analysis and interpretation of data, it was found that there were approximately six significant strategic changes during the study period. The causes of these changes were due to various reasons such as the need to reorganize the management structure, scaling the infrastructure of the institution to market reality. We conclude that the changes occurred from the managers' perception of the time, about the need to change the posture of the University, ie, the need to develop a new institutional mentality, reorganizing and redirecting their strategies. It was also observed that the institution needed to reorganize its management, enhancing the process of community participation in decision making of the organization, considering the characteristic institutional community.
\end{abstract}

Key-words: University. Strategy. Strategic Change. 


\section{INTRODUÇÃO}

Inseridas em um ambiente com competição acirrada e convivendo permanentemente com a instabilidade, as organizações enfrentam o desafio da mudança (DIDONET; BIANCHI; OLIVEIRA, 2001). As constantes transformações do mercado consumidor, e por consequência, dos produtos e padrões de concorrência, impelem as organizações para um terreno pouco conhecido, cujo ambiente empresarial encontra-se configurado por instabilidades e complexidades. Isso resulta na baixa previsibilidade e inter-relação entre os elementos ambientais, tornando mais difícil para as organizações a elaboração de estratégias que orientem seus negócios frente às condições ambientais. $\mathrm{O}$ ambiente em constante mudança pode levar ao fracasso as organizações que não se adaptarem ou se anteciparem às mudanças. Entender esse paradigma de constantes transformações torna-se fundamental para o sucesso das organizações (MELLO; CUNHA, 1997).

Assim, os estudos focados na mudança estratégica tornam-se cada vez mais importantes como fator de compreensão da sobrevivência das organizações, por existir uma crescente necessidade de antecipar-se às mudanças nas organizações, tendo em vista que, ao longo de sua história, as organizações possuem necessidades de mudar aspectos importantes de sua estratégia (FERREIRA; PEREIRA; LUCENA, 2004).

O tema "mudança estratégica" não é novo, nem tampouco seus conceitos básicos são atuais. No entanto, muito tem se discutido sobre o assunto, e novas técnicas e teorias tem surgido para facilitar a condução deste processo (LOPES; STADLER; KOVALESKI, 2003). Ao longo do tempo, formaram-se algumas opiniões divergentes, e outras complementares e evoluindo o pensamento sobre a mudança estratégica. Mintzberg, Ahlstrand e Lampel (2000), avaliam que, assim como existem diferentes classificações para a formulação de estratégias, existem também diferentes abordagens de mudança estratégica.

O processo de mudança estratégica é algo mais amplo do que puro entendimento de simples dimensões ambientais (HUTT; WALKER; FRANKWICK, 1995). Antes de tudo, a mudança estratégica é um processo político que implica a modificação da distribuição de recursos e de poder pelos vários níveis ou unidades organizacionais.

Nesse processo, o conjunto considerável de fatores externos à organização, no âmbito dos ambientes geral e específicos retêm fortes influências no comportamento da organização (WBATUBA, TRETER, SAUSEN, 2004; SAUSEN, 2003; RINGON, OLIVEIRA, 2004). Assim, as mudanças estratégicas aparecem como consequências da interpretação que os 
administradores fazem do ambiente, ou seja, de uma percepção e interpretação particular das condições objetivas dos ambientes geral e específico (DIVERIO; OLVEIRA, 2006).

As Universidades, como um tipo particular de organização (MINTZBERG, 1987), inseridas em um cenário imprevisível, necessitam, muitas vezes, repensar seu modo de atuação, com foco, também em curto prazo e a se conscientizar quanto à importância das questões estratégicas. O ambiente das organizações de ensino superior tem se alterado sobremaneira, tanto em nível de macro ambiente, como nível do ambiente de negócio. No nível macro ambiental, fatores de natureza política e tecnológica alteraram-se muito nos últimos anos, como a Lei de Diretrizes e Bases de Educação Nacional, o ensino a distancia, entre outros. Já no ambiente de negócio, pode-se destacar a expansão da concorrência, decorrente de uma política expansionista do ensino superior, $\mathrm{e}$ as consequentes transformações nas regras de competição no setor da educação.

Mudanças como essas, se refletem na realidade das instituições de ensino superior que, mais recentemente, tem constatado uma queda expressiva da relação candidato/vaga e, em decorrência, o excesso de vagas ociosas, alto valor das mensalidades e o esforço para garantir sustentabilidade financeira. Além do impacto que o ambiente exerce nas Universidades, cabe destacar que esta é uma instituição peculiar e diferente de outras organizações do setor comercial ou industrial (MINTZBERG, 1995). Isto porque a Universidade é caracterizada pela complexidade do trabalho operacional e das suas atividades-fim (ensino, pesquisa e extensão), além de ser cenário de disputas entre autores de diversas áreas do conhecimento e de possuírem objetivos variados e desconexos. As Universidades, como as demais organizações, também estão inseridas em um ambiente complexo e turbulento, que exige mudanças em função das contingências decorrentes dos fatores de ordem econômica e política. Profundamente influenciadas por estes fatores, as Universidades sentem-se cada vez mais pressionadas a promover mudanças estratégicas em níveis mais acelerados (DINIZ; CASTRO, 2010).

Com isso, a questão norteadora deste estudo configura-se no seguinte problema de pesquisa: Quais as principais mudanças estratégicas ocorridas em uma universidade comunitária nos últimos anos? Como objetivo central este artigo pretende verificar e analisar as mudanças estratégicas de uma Universidade comunitária localizada no interior do Rio Grande do Sul no período compreendido entre 2005 até 2011. 
Esse estudo está dividido em cinco seções. A primeira seção apresenta a introdução ao tema de estudo. A segundo seção apresenta a fundamentação teórica que sustentou a pesquisa. Já a terceira seção, apresenta a metodologia que foi utilizada para a pesquisa. A quarta seção é marcada pela analise dos dados coletados na pesquisa, e por último, às considerações finais, e referencias utilizadas nesta pesquisa.

\section{REFERENCIAL TEÓRICO}

\subsection{ADMINISTRAÇÃO ESTRATÉGICA}

Para Mintzberg (1987) é de natureza humana insistir na definição de todos os conceitos. A estratégia já existe há muitos anos (MINTZBERG; AHLSTRAND; LAMPEL, 2000) e para Mintzberg e Quinn (2001), não há uma única definição universalmente aceita para ela. De acordo com Maximiano (2010) o conceito de estratégia surgiu da guerra, onde a realização de objetivos significa superar um concorrente, no qual fica impedido de realizar os seus, pois cada um dos lados quer derrotar o outro. O conceito militar de estratégia determina a aplicação de forças em larga escala contra o inimigo (PEREIRA, 2004).

$\mathrm{Na}$ década de 50 o conceito de estratégia ganhou espaço no vocabulário das organizações (ANSOFF; MCDONNELL, 1993). No começo, o significado dessa palavra não estava claro. De acordo com seu uso no sentido militar, ela era definida como a "ciência e a arte do emprego de forças em uma guerra”. Fora desse contexto, a palavra estratégia é de uso corrente e indica uma forma de enfrentar um problema ou uma forma de realizar objetivos (MAXIAMIANO, 2010). Uma dessas formas é desenvolvida por Ansoff e McDonnell (1993), onde os autores definem a estratégia como basicamente um conjunto de regras de tomada de decisão para orientação do comportamento de uma organização. Uma dessas regras consiste nos padrões pelos quais o desempenho presente e futuro da organização é medido.

Assim, a partir dos anos 80, a administração estratégica ganha espaço no ambiente organizacional, deixando em segundo plano, grande parte da literatura existente. Embora aceitasse a maioria das premissas desenvolvidas anteriormente, os estudos sobre administração estratégica admitiram uma novidade, evidenciaram que a implementação das estratégias era tão importante quanto a sua formulação e, ao estudar o conteúdo, destacou o lado prescritivo do pensamento estratégico (LOBATO et al, 2006).

No passado, o processo de Administração Estratégica era influenciado em grande parte pelo departamento de planejamento das organizações. Os integrantes desses departamentos 
eram envolvidos pelo projeto e implementação dos sistemas de administração estratégica dentro de suas organizações. Porém, mais recentemente os departamentos de planejamento perderam um pouco de sua influência (CERTO et al, 2007).

Atualmente Administração Estratégica pode ser definida como um processo contínuo e interativo que visa manter uma organização como um conjunto apropriadamente integrado a seu ambiente. O processo atual de administração estratégica tende, especialmente, em organizações de menor porte, a ser dominado pelo presidente da companhia. Ele é também considerado primeiramente como o principal responsável pelo sucesso do processo. Entretanto, isso não significa que o presidente executa o processo de administração estratégica sozinho, pelo contrário, o presidente bem sucedido geralmente esboça um processo de administração estratégica que envolve membros de diversas áreas e diferentes níveis da organização (ALDAY, 2000).

O processo de administração estratégica consegue criar e aperfeiçoar um conjunto de ferramentas analíticas para ajustar a estratégica genérica às condições vigentes no ambiente de negócios. Destacam-se assim, os seguintes aspectos: (1) analise da estrutura da indústria; (2) estratégias competitivas - posições genéricas - mercado; (3) o contexto econômico e altamente competitivo no qual as organizações obtêm margens de lucro baseadas no gerenciamento da cadeia de valor (LOBATO et al 2006).

Com isso, a organizações podem obter diversos benefícios praticando de forma correta a administração estratégica. Talvez o mais importante seja a tendência de tais organizações aumentarem seus níveis de lucro. Embora estudos anteriores tenham concluído que o aumento da lucratividade normalmente não acompanha a aplicação da administração estratégica, um significativo número de pesquisas recentes sugere que um eficiente e efetivo sistema de administração estratégica pode aumentar a lucratividade (ALDAY, 2000).

\subsection{MUDANÇA ESTRATÉGICA}

Ao longo de sua trajetória de desenvolvimento, as organizações possuem necessidades de mudar aspectos importantes de sua estratégia de forma a se adaptar as necessidades ambientais e a buscar eficiência em suas operações (FERREIRA; PEREIRA; LUCENA, 2004). Em décadas passadas, as organizações operavam em ambientes estáveis, no qual a previsibilidade era possível e as regras eram determinadas (DIDONET; BIANCHI; OLIVEIRA, 2001). Já na atualidade, as organizações se defrontam com um quadro de 
mudanças que exige maior capacidade de adaptação às contingências e imposições do ambiente e também preparo profissional para enfrentar os desafios do ambiente competitivo (WBATUBA; TRETER; SAUSEN, 2004).

Segundo Motta (1997), a mudança de estratégia na organização pode: (1) surgir como produto de ideias direcionadas e planejadas; (2) originar da necessidade de se resolver problemas, tendo em vista a importância de se reagir a situações problemáticas; ou (3) emergir do processo de circulação de ideias, tendendo a preconizar modelos menos dependentes de programação gerenciais. Os motivos de qualquer mudança estratégica em uma organização estão dentro da própria organização ou no ambiente em que ela está inserida, ou também como combinação de ambos os fatores. A mudança estratégica causada por estas forças vai depender de sua natureza e intensidade, mais também de sua própria capacidade e versatilidade da organização em enfrentá-las (LOPES; STADLER; KOVALESKI, 2003).

A mudança estratégica pode significar desde uma alteração de posição no mercado em que está inserida, mudança em sua função social, como uma possível alteração em sua missão ou mudança em sua cultura (LOPES; STADLER; KOVALESKI, 2003). As mudanças de estratégia também podem variar desde o aparecimento de um novo executivo principal, que deseja imprimir seu estilo de gerenciar na organização, até o constante declínio de desempenho da organização, que acaba exigindo uma mudança descontínua, ou uma readequação geral da organização (MINTZBERG; QUINN, 2001).

Para Rossetto et al (1996) a mudança estratégica é entendida como um fenômeno no qual envolve esforços no sentido da alteração dos modos vigentes de cognição e ação pelos membros da organização, no sentido da obtenção de vantagens de oportunidades ou de superação de desafios ambientais. Deve ser salientado também que no processo de mudança estratégica, o conjunto considerável de fatores externos à organização, no âmbito dos ambientes geral e específicos retêm forte influências no comportamento da organização (WBATUBA; TRETER; SAUSEN, 2004; RIGON; OLIVEIRA, 2004). Por esta razão, as mudanças estratégicas são consequências da interpretação que os administradores fazem do ambiente, ou seja, de uma percepção e interpretação particular das condições objetivas dos ambientes geral e especifico (DIVERIO; OLVEIRA, 2006).

As organizações estão inseridas em ambiente instáveis e de intensa mudança, tomados de descontinuidade de tempo e incertezas, fazendo com que elas passem por transformações organizacionais que são as adaptações das mudanças no ambiente competitivo e visam à 
reestruturação e sobrevivência da organização (DIDONET; BIANCHI; OLIVEIRA, 2001). Segundo Sausen (2003), a mudança estratégica configura-se como um fenômeno importante na analise dos processos de mudança organizacional e imperativo de sobrevivência e crescimento das organizações.

Assim, a mudança estratégica tem sido um dos principais diferenciais para que as organizações permaneçam em um mercado cada vez mais competitivo, trazendo inclusive, reflexos no desenvolvimento econômico e social de uma região ou país. Ela aparece não só como inevitável, mas também necessária à sobrevivência das pessoas e instituições (PEREIRA; et al, 2010).

\section{METODOLOGIA DA PESQUISA}

Esta pesquisa tem como objetivo verificar e analisar as mudanças estratégicas ocorridas em uma Universidade Comunitária do interior do Rio Grande do Sul. Para isso, optou-se por uma pesquisa qualitativa, pois de acordo com Marconi e Lakatos (2004) ela preocupa-se em analisar e interpretar aspectos mais profundos, descrevendo a complexidade do comportamento humano, fornecendo uma analise mais detalhada sobre as investigações, hábitos, atitudes e tendências de comportamento. Entre as diferentes formas de pesquisa qualitativa, optou-se pelo estudo de caso único (MARCONI; LAKATOS, 2004). O estudo de caso qualitativo permite a investigação, uma vez que este tipo de pesquisa qualitativa se diferencia pela delimitação do objetivo de estudo, o caso (MERRIAM, 1998, p. 27), e que esta delimitação, caracterizada por uma unidade social deve ser analisada intensivamente (GODOY, 1995, p. 25). A população- alvo da pesquisa compreende os gestores da unidade de análise eleita para este estudo, a saber, uma Universidade Comunitária localizada na região Noroeste do estado do Rio Grande do Sul. Foram selecionados oito gestores que estavam presentes na organização durante o período do estudo, que compreende os anos de 2005 a 2011. Os entrevistados selecionados foram: (a) Presidente e vice-presidente da Fundação da gestão 2008/2010 e 2011/2013; (b) Reitor e vice-reitores da gestão 2008/2010 e 2011/2013; (c) Presidente do conselho curador; (d) Contador da Gestão 2008/2010 e 2011/2013.

\subsection{COLETAS E ANALISE DOS DADOS}

A coleta de dados foi realizada através de entrevistas semiestruturadas com os gestores da Instituição. A entrevista semiestruturada apresenta certo grau de estruturação, já que se 
guia por uma relação de pontos de interesse que o entrevistador vai explorando ao longo de seu curso (GIL, 1999, p. 120). Porém, ela permite uma liberdade por parte do entrevistador para desenvolver varias situação em qualquer direção que considere adequado (MARCONI; LAKATOS, 2004).

Por fim, para serem analisados os dados, as entrevistas foram gravadas e transcritas para serem analisadas através da analise de conteúdo. A análise de conteúdo compreende uma técnica de investigação que, por meio de uma descrição objetiva, sistemática e qualitativa do conteúdo das comunicações, tem por fim a interpretação destas comunicações (BARDIN, 1977). Tem tem o intuito de entender mais profundamente um discurso e captar diversas percepções possíveis (GODOY, 1995). Sendo assim, as transcrições das entrevistas, submetidas à análise de conteúdo, resultou em categorias de análise, denominadas: Primeira mudança - Reforma do Estatuto; Segunda Mudança - Divisão dos cursos em quatro centros de ensino; Terceira mudança - Redimensionamento da infraestrutura da Instituição; Quarta mudança - Ampliação da qualidade do ensino; Quinta mudança - Profissionalização da gestão e do corpo técnico; Sexta mudança - Estratégia política-institucional.

\section{ANALISE DOS RESULTADOS}

As mudanças estratégias que ocorreram na instituição, a partir da administração judicial, onde então Reitor da instituição no ano de 2005, juntamente com demais membros daquela gestão, foram afastados das funções administrativas. Esse episódio foi relatado pelos entrevistados como a maior crise vivida pela organização. Essa crise teve várias facetas, pois representa primeiramente, uma crise política interna decorrente, entre outros fatores, de que o ordenador de despesas, ou seja, a pessoa que ocupava o cargo tanto de reitor quanto de presidente da fundação, não estava fazendo valer o seu papel, sendo assim ocorria desvio de funções.

Cita-se também, uma crise financeira interna, pois naquele momento em 2005, gastava-se muito mais do que se arrecadava. Ainda existe a crise judicial, que é uma consequência da crise política e financeira, que geraram demanda judicial a partir do descontrole do processo gerencial da organização. E por último, ocorre a crise do ensino superior, que afeta não apenas essa Universidade, mas grande parte das Instituições de Ensino Superior privadas no Brasil. Essa crise no ensino superior é causada principalmente pela 
queda na taxa de natalidade a partir dos anos 90, pelo aumento na oferta de vagas de instituições públicas e a entrada do ensino a distância, ofertada por algumas Instituições.

A partir desses quatro fatores impulsionadores, a Organização a entrou em um processo de mudança de suas estratégias, onde uma das primeiras discussões foi à separação entre a Instituição e Fundação, para evitar que aconteça o que foi evidenciado naquele momento em 2005, uma crise gerada por abuso de poder.

\subsection{PRIMEIRA MUDANÇA - REFORMA DO ESTATUTO}

Pode-se verificar que a primeira mudança encontrada no período foi a reforma do estatuto, que começou a ser discutida pelos gestores da organização, já em 2006 com a administração judicial, e tinha como objetivo a separação entre Instituição e Fundação da Universidade. Essa separação foi implantada em 2008, sendo que a partir desse momento o Reitor da Universidade e o Presidente da Fundação passam a ser cargos eletivos, ocupados por pessoas diferentes. Nesta configuração a Instituição tem por objetivo responsabilizar-se pelas questões de ensino, e a Fundação trata de se responsabilizar das questões financeiras. Até 2005 a Universidade e Fundação era a mesma Instituição, e a mesma pessoa acumulava o cargo de Reitor e Presidente da Fundação, havendo assim, uma concentração de poder exacerbada em uma pessoa.

A partir da divisão entre Instituição e Fundação, criou-se, dentro da fundação o conselho curador com 26 membros, 13 da comunidade interna, e 13 da comunidade externa à Universidade. Esses membros 26 são compostos de representações múltiplas, onde na Universidade, os componentes são: a Reitora, professores eleitos, funcionários, também eleitos e estudantes. As instituições públicas da comunidade externa que participam com membros são: a Câmara de Vereadores, a Prefeitura, os órgãos de classe como a Ordem dos Advogados do Brasil (OAB), o sindicato dos Comerciantes e o Conselho de Economia. Assim, esses 26 membros elegem o conselho diretor, ou seja, três do total de vinte e seis, que ao serem eleitos, são designados ao conselho curador e conselho diretor, nos cargos de Presidente, Vice-Presidente e Conselheiro Titular.

\subsection{SEGUNDA MUDANÇA - DIVISÃO DOS CURSOS EM QUATRO CENTROS DE ENSINO}

Junto da reforma dos estatutos, onde se separou a Instituição Universidade da Fundação Universidade, emerge a segunda mudança significativa para a Universidade, que foi 
a divisão dos cursos de graduação, em quatro centros, divididos por afinidades. Essa decisão começou a ser discutida em 2006 e foi colocada em pratica a partir de 2008. Então, os centros se dividiram em: (1) centro de ciências sócias aplicadas; (2) centros de ciências agrárias, exatas e da terra; (3) centro de ciências da saúde; (4) centro de ciências humanas e comunicação.

Essa divisão foi uma mudança de suma importância, tendo em vista que resultou em maior organização e entendimento dos cursos, pois até 2005, havia na Universidade má definição dos cursos, alguns estavam classificados como Faculdade, e outros faziam parte de centros. Além disso, essa mudança estratégica possibilitou uma estrutura intermediária entre a reitoria e os cursos, e também entre os próprios cursos, havendo uma aproximação entre eles, otimizando a tomada de decisão e divisão de recursos.

\subsection{TERCEIRA MUDANÇA - REDIMENSIONAMENTO DA INFRAESTRUTURA DA INSTITUIÇÃO}

A terceira mudança estratégica importante, ocorrida na organização em estudado foi a mudança de postura da Universidade frente a sua comunidade, que se trata da adequação da infraestrutura da Instituição com a sua demanda de alunos. Até o momento da administração judicial, a Universidade contava com cerca de cinco mil alunos, porém segundo os entrevistados, $40 \%$ (quarenta por cento) não realizavam o pagamento das mensalidades, este fato se concretizava tendo em vista a concessão de benefícios como bolsas, ou simplesmente pelo fato de não serem cobrados.

As reestruturações no setor financeiro acarretaram perdas de alunos, entretanto, essa queda no número de alunos foi até mesmo positiva, pois segundo os entrevistados, a Universidade passou a ter uma receita condizente com o tamanho da Instituição, isso possibilitou a readequação na folha de pagamento, tendo em vista que ao reduz o número de alunos, o número de professores e funcionários também foi reduzido, podendo assim, fazer jus aos compromissos financeiros da instituição como um todo.

Outra mudança na adequação da infraestrutura da Universidade foi pelo fato de que os gestores da Universidade entenderam que havia, e ainda há, uma redução natural na demanda de alunos pelo ensino superior. O primeiro motivo para essa redução se dá pela queda da taxa de natalidade a partir dos anos 90. E outro fator determinante, na visão dos gestores, foi o aumento da oferta de vagas nas instituições públicas de ensino, e também a entrada do ensino a distância, ofertadas por algumas Universidades. 
Os antigos gestores da Universidade, antes do período de 2005, planejavam a política de expansão da Instituição, com a intenção de aumentar a oferta de cursos e até mesmo a ocupação de áreas em outros municípios. Os atuais gestores entendem que estrategicamente, a melhor decisão é recuar, devido aos problemas com demanda já citados, buscando em primeiro momento consolidar as mudanças promovidas.

\subsection{QUARTA MUDANÇA - AMPLIAÇÃO DA QUALIDADE DO ENSINO}

A quarta mudança constatada a partir das entrevistadas com os gestores da organização, foi uma mudança de estratégia muito forte que se refletiu sobre a qualidade do ensino oferecido pela a Instituição. Até o momento, a Instituição passa por certo descaso com relação ao ensino. Havia cursos novos que, porém não passaram pela avaliação institucional, e todos os cursos estavam com seus prazos de validade vencidos, e a estrutura pedagógica abandonada.

A partir de 2006, iniciou-se um trabalho de qualificação do ensino, qualificação da gestão, buscando trazer um corpo docente mais qualificado, e também qualificar ainda mais o corpo docente que já estava na Instituição, atendendo a todos os critérios do percentual de doutores e mestres exigido legalmente.

Outra ampliação da qualidade do ensino na Instituição foi na área de pós-graduação, pesquisa e extensão, onde diversas mudanças foram instituidas como, regulamentação de funcionamento da extensão, implantação de programas de ficção de permanência de doutores, programa de auxilio a publicação, e o por fim em 2011, a aprovação dos cursos de mestrado na Instituição. Todas essas mudanças estratégicas, foram implantadas a partir de 2006, com o objetivo de qualificar o ensino, a pesquisa e extensão e fortalecer a Instituição frente ao mercado competitivo.

\subsection{QUINTA MUDANÇA - PROFISSIONALIZAÇÃO DA GESTÃO E DO CORPO TÉCNICO}

A quinta mudança se caracterizou pela profissionalização e também, qualificação da gestão e do corpo técnico, como a estratégia de redimensionar para cada área, profissionais realmente capacitados para determinada atividade, com subsidio da ferramenta de descrição de cargos.

Anteriormente, haviam cargos da administração e contabilidade, que não eram exercidos por profissionais especializados que a Universidade tinha por manter os seus cursos 
de Economia, Contábeis e Administração. Essa adequação passou a ser realizada com todo o corpo técnico administrativo, através de seleção pública. Assim, a Instituição passou a buscar gestores qualificados e especializados para ocupar determinadas áreas, e o mesmo aconteceu com o seu corpo técnico administrativo, sendo contratados apenas via concursos público.

\subsection{SEXTA MUDANÇA - ESTRATÉGIA POLITICA-INSTITUCIONAL}

A sexta mudança constatada foi à estratégia politica-institucional desenvolvida pelos gestores da organização. Com o acumulo da divida tributária que a organização contraiu até o período de 2008, adotou-se a estratégia de buscar parceiros na região através de suas lideranças políticas, no qual tinha por objetivo principal trazer soluções para seu endividamento tributário. Essa mudança na relação da organização com a região e comunidade onde está inserida, teve um desfecho favorável no ano de 2012, através da criação de um programa do governo federal (PROIES), que permite a negociação das dividas das Universidades, em troca de bolsas acadêmicas.

\section{CONSIDERAÇÕES FINAIS}

Ao findar este estudo, que tinha a intenção de identificar as principais mudanças estratégicas ocorridas em uma Universidade comunitária, visualizou-se que as mudanças ocorreram em diversas áreas da organização, como na sua infraestrutura, na estrutura organizacional, na política de gestão, na política de ensino, nas finanças, tais mudanças também refletiram em alterações na cultura organizacional. Essas mudanças de estratégia começaram a ser realizadas a partir no ano de 2006, após a imposição da administração judicial pelo Ministério Público, e tendo continuidade em 2008 com as eleições da Instituição, e da Fundação.

Assim, foi constatado, através das narrativas dos entrevistados, que as principais mudanças de estratégias da Instituição no período compreendido entre os anos de 2005 a 2011 foram: (1) Reforma do estatuto; (2) Divisão dos cursos em quatro centros de ensino; (3) Redimensionamento da infraestrutura da Instituição; (4) Ampliação da qualidade do ensino; (5) Profissionalização da gestão e do corpo técnico; (6) Estratégia politico-institucional.

A primeira mudança identificada foi a reforma do estatuto, implantada em 2008, ocorreu pela necessidade de separar a Instituição da Fundação. Até o ano de 2005, uma mesma pessoa ocupava o cardo de Reitor e presidente da Fundação, causando certos conflitos 
internos, assim como o acumulo de poder, situação que se tornou insustentável ocasionando o afastamento desse gestor.

A mudança seguinte tratou da divisão dos cursos de graduação da Universidade em quatro centros de ensino. Até 2007, todos os cursos da Instituição desconexos, não se tinha organização quanto a isso. Alguns cursos eram considerados faculdades, outros estavam dentro de centros, então, realizou-se a união de todos os cursos da Instituição em quatro centros de ensino, divididos conforme as áreas do conhecimento.

O redimensionamento da infraestrutura da Instituição aconteceu a partir de 2006. Essa mudança aconteceu por dois motivos. O primeiro foi pelo fato de que alguns alunos até 2005, que não realizavam seus pagamentos em dia, e outros alunos, tinham bolsas de estudos obtidas de forma escuso, o que acarretou uma diminuição automática no número de alunos. $\mathrm{O}$ outro motivo foi pela avaliação dos gestores da Instituição, de que não havia demanda suficiente para determinados cursos, assim, esses cursos foram descontinuados.

A quarta mudança estratégica foi à ampliação da qualidade do ensino e readequação dos cursos oferecidos. Os cursos de graduação da Instituição estavam com seus reconhecimentos vencidos perante o Ministério da Educação, e os novos cursos não haviam sido avaliados. Então, foi instituído um esforço de qualificação do ensino, buscando transformar essa realidade vivida até meados do ano de 2005, e também, começou a busca pela criação de cursos de mestrado, que se efetivou em 2011. A mudança estratégica de profissionalização e qualificação da gestão e do corpo técnico se deu pela necessidade de colocar gestores especializados e qualificados nas diversas áreas da Instituição. Outro fato que marcou nessa mudança, foi à contratação do corpo técnico-administrativo através de seleção pública.

A última mudança foi descrita como uma estratégia politico-institucional. O motivo pelo qual levou a Instituição a adotar essa estratégia foi a necessidade de saldar suas dividas tributárias, levando a Instituição a adquirir um relacionamento mais próximo com as lideranças políticas da região, buscando soluções para seu endividamento tributário.

Sendo assim, em reposta ao objetivo da pesquisa, pode se dizer que foi alcançado, pois foi possível verificar e analisar as mudanças estratégicas ocorridas em uma Universidade Comunitária do Rio grande do Sul. Cabe ressaltar que essa pesquisa possibilitou verificar como uma Instituição de Ensino Superior se comportou a partir de um período considerado critico em sua história. Verificou-se através das narrativas dos gestores da Instituição desde a 
intervenção judicial, certa maturidade para lidar com os obstáculos sofridos pela organização. Observou-se o entendimento dos novos gestores a cerca da necessidade de imprimir mudanças na postura da Universidade, sendo necessário desenvolver uma nova mentalidade dentro da Instituição, reorientando suas estratégias. No período estudado, observou-se também que a Instituição adaptou seu modo de gerir, sendo que por ser uma Instituição comunitária, toda a comunidade interna quanto externa, precisa ter voz ativa.

Ao findar este estudo, acredita-se ter contribuído na identificação das principais mudanças estratégicas vivenciadas em uma Instituição de ensino privada. Entretanto, por se configurar como um estudo de caso único, os resultados aqui encontrados não poderão ser generalizados. Sendo assim, como sugestão de futuros estudos sobre tema "mudança estratégica", que é inevitável para as organizações nos dias de hoje, sugere-se a realização de um estudo multicaso em organizações que possuem as mesmas características. Assim como, estudos que identifiquem de forma mais aprofundada a repercussão cotidiana das mudanças estratégicas nas organizações, buscando a percepção dos colaboradores.

\section{REFERNCIAL}

ALDAY, Hernan E. Contreras. O Planejamento Estratégico dentro do conceito de Administração Estratégica. Revista FAE. Curitiba-PR. v. 3, n. 2, p. 9-16.maio 2000.

ANSOFF, H. Igor; MCDONNELL, Edward J. Implementando a Administração Estratégica. São Paulo: Atlas, 1993.

CERTO, Samuel C; ET AL. Administração Estratégica. 2 ed. São Paulo: Pearson, 2007.

DIDONET, Simone Regina; BIANCHI, Renata Coradini; OLIVEIRA, Luiz Carlos Pistóia. A mudança organizacional como imperativo de sobrevivência: o caso de uma indústria manufatureira. In: XXI ENCONTRO NACIONAL DE ENGENHARIA DE PRODUÇÃO. Anais eletrônicos... 2001, Salvador - BA

DINIZ, Daniela Martins; CASTRO, José Marcio de. Processo de Gestão Estratégica em Universidades Privadas: Um Estudo de Casos. Revista de Administração da Universidade Federal de Santa Maria. Santa Maria - RS, v. 3, n. 3. 2010, p. 311-325.

DIVERIO, Tamara Silvana Menuzzi; OLIVEIRA, Luiz Carlos Pistóia de. Mudança Estratégica Organizacional: um estudo de caso na cooperativa castilhense. In: XXVI ENCONTRO NACIONAL DE ENGENHARIA DE PRODUÇÃO. 2006, Fortaleza - CE.

FERREIRA, Wagner Ramos; PEREIRA, Yákara Vasconcelos; LUCENA, Eduardo de Aquino. Mudança Estratégica em Pequenas Empresas. In: XI SIMPOSIO DE ENGENHARIA DE PRODUÇÃO. Anais eletrônicos... 2004, Bauru - SP. 
GIL, Antonio Carlos. Métodos e técnicas de pesquisa social. 5 ed. São Paulo: Atlas, 1999.

GODOY, A. S. Pesquisa qualitativa: Tipos fundamentais. In: Revista de administração de empresas.São Paulo, v. 35, n. 3. 1995, p. 20-29.

HUTT, M. D; WALKER, B. A.; FRANKWICK, L. G. Hurdle the cross-functional barriers to strategic change.Sloan Management Review. v. 36, n. 3, p. 22-30, Spring, 1995.

LOPES, Paulo Cesar Barbosa; STADLER, Carlos Cesar; KOVALESKI, João Luiz. Gestão da Mudança Organizacional. Revista Publicatio: Ciências Humanas, Linguística, Letras e Artes. Ponta Grossa - PR.vol 11, nº 1.Jun, 2003.

MARCONI, Marina de Andrade; Lakatos, eva Maria. Metodologia Cientifica. 4 ed. São Paulo: Atlas, 2004.

MAXIMIANO, Antônio Cesar Amaru. Teoria Geral da Administração. São Paulo: Atlas, 2010

MELLO, Rodrigo Bandeira; CUNHA, Cristiano J. C. de Almeida. Um Framework para o estudo da Mudança Estratégica em pequenas empresas de construção de edificação.XVII Encontro Nacional de Engenharia da Produção. 1997, Gramado - RS.

MERRIAN, S. Qualitative research and Case Study Applications in Education.San Francisco: Jossey-Bass, 1998.

MINTZBERG, Henry. Estratégia Artesanal. In; MINTZBERG, H.; QUINN, J. B. O processo da Estratégia. E ed. Porto Alegre: Bookaman, 2001. p. 114-122.

. Os 5P's da Estratégia. In: MINTZBERG, H.; QUINN, J. B. O processo da Estratégia. 3 ed. Porto Alegre: Bookman, 2001. p. 26-32.

MINTZBERG, Henry; AHLSTRAND, Bruce; LAMPEL, Joseph.Safari de Estratégia: Um roteiro pela selva do planejamento estratégico. Porto legre: Bookman, 2000.

MINTZBERG, Henry; QUINN, James Brian. O processo da estratégia. 3 ed. Porto Alegre: Bookman, 2001.

LOBATO, David Menezes; ET AL. Estratégias de Empresas. 7. Ed. Rio de Janeiro: FGV Management, 2006.

PEREIRA, Anna Maris. Introdução à Administração. 3. Ed. São Paulo: Pearson, 2004.

PEREIRA, Mauricio Fernandes; RIBEIRO, Mariluce Lemos Guetten; LISONI, Juliano;CARIO, Silvio Ferraz. O processo de Mudança e Adaptação Estratégica em uma empresa familiar Brasileira: o caso da Reunidas S/A. Revista Organizações em Contexto. vol $6, n^{\circ} 11$, Jan. 2010 
RINGON, Cleide Marisa; OLIVEIRA, Luiz Carlos Pistóia. Mudança estratégica: o caso do setor alcooleiro. In: I SEMINÁRIO DE GESTÃO DE NEGÓCIOS. Anais eletrônicos... 2004, Curitiba, PR.

ROSSETTO, Carlos Ricardo; ET AL. Os elementos da mudança estratégica empresarial: um estudo exploratório. Revista Teoria e Evidencia Econômica. Passo Fundo, v. 4, n. 7/8, p. 111-120, maio/dez, 1996.

SAUSEN, Jorge Oneide. Adaptação estratégica organizacional: um estudo histórico interpretativo. RevistaDesenvolvimento em Questão. Unijuí, v. 1, n. 2, p. 203-230, jul/dez, 2003.

WBATUBA, Berenice Rossner; TRETER, Jaciara; SAUSEN, Jorge Oneide. Mudança estratégica organizacional: analise de um período histórico estratégico da cooperativa regional tritícola Serrana Ltda- Cotrijuí. Revista Desenvolvimento em Questão. Ijuí, v. 2, n. 3, p. 149-177, jan/jun, 2004. 